\title{
REPRESENTACIONES SOCIALES DE LOS MAYORES SOBRE LOS PROGRAMAS SOCIALES EN LA CIUDAD DE BUENOS AIRES.
}

\author{
María Julieta Oddone ${ }^{1}$ \\ Lilia Chernobilsky ${ }^{2}$
}

En este artículo analizamos las representaciones sociales que tienen las personas mayores que habitan en la Ciudad de Buenos Aires con respecto a los planes sociales destinados a este grupo de edad. Se basa en resultados parciales de una investigación mayor que tuvo como objetivo obtener información sobre el uso, la imagen, el papel de las redes sociales y las estrategias de supervivencia de los adultos mayores en relación con los mencionados programas sociales. ${ }^{3}$

Se entiende a la política social como la “intervención del Estado, instrumental y normativa con intencionalidad compensatoria y/o redistributiva que ordena medios para realizar aspectos concretos del Bienestar Social" ${ }^{4}$. En este sentido, existe una fuerte relación entre política social y bienestar como un concepto comprendido y compartido socialmente. Por ello, el peso que tiene en las sociedades capitalistas la protección social se debe a que su alcance implica un papel central en la distribución del bienestar al que acceden los distintos grupos y resulta ser un indicador del tipo de sociedad de que se trata. (Danani y Grassi, 2018: 291)

Si tenemos en cuenta su performatividad, las políticas sociales hacen sociedad (Danani, 2008: 40) y tanto las acciones como las omisiones de cada política social construyen sentidos y conforman sujetos individuales y sociales al mismo tiempo que se consolida un imaginario colectivo, construyendo nuevas realidades.

Para Adelantado, (2008: 13) la política social se muestra como un instrumento capaz de incidir en la composición de la estructura social, porque opera como principio organizativo de los sectores otorgando a cada uno de ellos determinada responsabilidad en la satisfacción de necesidades. En el sector mercantil la política social interviene a través de

\footnotetext{
${ }^{1}$ FLACSO-CONICET (Consejo Nacional de Investigaciones Científicas y Técnicas/Universidad de Buenos Aires (Argentina).

${ }^{2}$ CEIL (Centro de Estudios e Investigaciones Laborales).

${ }^{3}$ Los datos utilizados fueron recabados en el marco del Proyecto UBACyT denominado "Seguridad Social, Políticas Sociales y Redes de Apoyo en la Vejez. Un análisis integral entre programas Institucionales y actores” dirigido por María Julieta Oddone y codirigido por Lilia Chernobilsky.

${ }^{4}$ Seminario Taxonómico sobre el Bienestar Social 1987, p. 175
} 
la definición de qué es o no una mercancía, en el estatal mediante disposiciones jurídicas que ponen bajo la responsabilidad del Estado determinados bienes o recursos, y en el sector informal o voluntario estableciendo por defecto un espacio social de intercambio altruista de bienes, que no son concebidos como mercancías o derechos. Mediante la política social se pueden transformar lo que eran derechos (sanidad, educación, pensiones) en mercancías (reduciendo la intensidad protectora y desregulando el servicio público), o dejar en manos del mercado, la familia (es decir, las mujeres), o el tercer sector la respuesta a los nuevos y viejos problemas sociales (pobreza, diversificación de los tipos de familia, envejecimiento de la población).

Específicamente orientada a las personas mayores, Ursula Lehr (1999: 350) plantea que una política para la vejez debe ser más que una política de cuidados y no debe limitarse sólo a los aspectos financieros. La longevidad conlleva desafíos como: a) mantener y aumentar la independencia de las personas de edad para asegurar una vejez con buena salud, brindando servicios que permitan alentar una vejez activa basada en los recursos propios del individuo; b) extender y mejorar las medidas de readaptación -en los casos donde haya alguna discapacidad- para permitir a las personas de edad recuperar una vida autónoma y; c) encontrar respuestas a los problemas planteados por los ancianos frágiles y dependientes incluyendo servicios que apoyen a las familias cuidadoras y/o, al entorno que se ocupa de la persona de edad. Subyace en estos tres puntos una conceptualización de la vejez según la cual, esta etapa debe prolongar y mantener, en todo lo posible, el estilo y la calidad de vida de la mediana edad. Se fundamenta teóricamente en el envejecimiento productivo y el envejecimiento activo.

En este sentido, las políticas sociales tienen el papel de actuar como transformadoras del rol social de los diversos grupos, particularmente los ancianos, y su estudio se torna relevante porque las políticas públicas influyen en la construcción social de la vejez y su lugar en la sociedad. En esta línea, el objetivo de nuestra investigación apuntó a analizar la utilización de los planes sociales para las personas mayores y las representaciones que estas personas tienen con respecto a los mismos.

Por otra parte, las representaciones sociales, como formas de conocer el mundo, pueden caracterizarse como elaboraciones psíquicas donde se integran la experiencia personal con los valores e informaciones que circulan en la sociedad. De este modo, las 
significaciones que conforman la representación están impregnadas de valores, ideales y prejuicios que orientan las actitudes y comportamientos de los sujetos. (Gastrón, et all. 2012: 119)

Las representaciones sociales se constituyen según los grupos sociales, como sistemas de códigos diversos, esto es, sistemas clasificatorios que obedecen a distintas lógicas, distintos principios interpretativos y valores orientadores de las prácticas. En el sistema social algunos grupos comparten un campo representacional donde se generan elementos comunes y propios que se crean en torno a cada objeto social, el cual aloja saberes de distintos orígenes y cualidades, influidos a su vez por distintos factores como el género, la historia individual y social, el nivel educativo, la clase social, entre otros.

En la representación social pueden coexistir, distintas imágenes e ideas sin tender a la uniformidad. Se puede pensar en cierto nivel de consenso básico que es el que hace posible la interacción y la comunicación y que aporta el predominio de ciertos elementos significantes según la circunstancia socio - cultural dominante. De todos modos este predominio es visiblemente temporario ya que el devenir de estas circunstancias impide que sea definitivo. (Lombardo \& Monchietti, 2015: 54)

En síntesis, las significaciones que componen la representación social de un objeto son moldeadas en función de su condición de ser producidas en grupos determinados. Las representaciones sociales se describen en términos de estructuras significantes que habilitan la identificación de los grupos que las construyen y de los contenidos de las mismas. De este modo, son funcionales a la construcción de las identidades sociales. (Gastrón, et all. 2012: 120; Lombardo \& Monchietti, 2015: 56) En este sentido, analizar las representaciones sociales que poseen las personas de mayor edad con respecto a los planes sociales resulta pertinente para orientar la política social.

\section{Metodología y Resultados}

La investigación, que dio origen al presente artículo, se basó en los siguientes objetivos: a) Generar información actualizada de las características de las personas mayores a través de un estudio representativo de la población que permita dar cuenta desde aspectos sociodemográficos hasta distintos aspectos de su situación personal. b) Describir y analizar las diferentes estrategias de supervivencia que esgrimen los actores sociales y el papel que 
cumplen las redes sociales de apoyo en la resolución de las exigencias de su vida cotidiana, teniendo en cuenta las diferencias producidas por el nivel socioeconómico, el género, la edad y autonomía de dichos actores. Y, c) Analizar las representaciones que los actores tienen en relación con los planes sociales y la obra social de los jubilados.

Con el fin de obtener profundidad y representatividad sobre los temas planteados se utilizó una estrategia de métodos mixtos ${ }^{5}$.

En primer lugar, se obtuvo información cualitativa de los adultos mayores a través de las siguientes técnicas: a) entrevistas abiertas, a través de las cuales, en una situación lo más semejante posible a aquélla en que se produce el lenguaje natural, pretendemos determinar las características que asumen los procesos de construcción de la identidad personal, social, laboral en los relatos de vida; captar el significado que el actor otorga a su acción y la de otros y conocer los motivos que determinaron y orientaron esa acción. b) observación directa, mediante la que intentamos acceder a la naturaleza de las relaciones y de los procesos en diferentes contextos, comprendiendo los significados y funciones de la acción social, al mirarla en el transcurso de la entrevista y; c) la técnica de historias de vida que consiste en el uso de relatos biográficos hechos por los informantes. (Oddone, 2014: 359)

Las entrevistas fueron realizadas siguiendo una guía abierta, específica para el objetivo de la investigación, que abarcó:

a) Datos del entrevistado: datos sociodemográficos y económicos (edad, sexo, educación), características de la vivienda y clima del entorno, lugar de nacimiento, migraciones y el contexto de la migración. Oficios y conocimiento de oficios y artes.

b) Composición e historia de la familia y de redes sociales de apoyo: historia familiar (antecedentes familiares, origen familiar para rastrear estrategias de supervivencia, evolución socio económica). Situación familiar actual. Grupos de amigos y vecinos.

\footnotetext{
${ }^{5}$ Los aspectos metodológicos utilizados en la implementación de los métodos mixtos de la investigación pueden encontrarse desarrollados en el trabajo presentado en el V Encuentro Latinoamericano de Metodología de las Ciencias Sociales. Universidad Nacional de Cuyo. Mendoza, 16 al 18 de noviembre de 2016 Oddone, M. y Chernobilsky, L. (2016) Estrategia informática para la combinación de datos cualitativos y cuantitativos. Una visión de los adultos mayores sobre Políticas Sociales. En Revista de Ciencia y Técnica http://www.21.edu.ar/investigacion-ponencias-congreso-investigacion-cualitativa-ciencias-sociales.html También en Chernobilsky, L., (2019) Estrategia informática para la combinación de datos cualitativos y cuantitativos: ¿Software mixto o combinación desoftware? en I. Vasilachis de Gialdino (Coord.), Estrategias de investigación cualitativa 2, Barcelona, Gedisa. Pp 327-371.
} 
c) Historia laboral: edad de inicio laboral, trayectoria laboral, tiempo y condiciones de trabajo, entrada y salida del mercado laboral. Cuestiones ligadas a la jubilación y monto recibido, aportes provisionales.

d) La salud tal como es percibida por ellos, atención y visión sobre su atención. Situación frente a la seguridad social.

e) Resolución de la vida diaria y cambios de hábitos de consumo: planes sociales, ayuda familiar, ahorros, alquileres, etc. Cambios en pautas alimentarias y de salud, cambio de vivienda, etc.

f) Tiempo libre y su utilización, participación social y voluntariado. Utilización de la técnica del día de ayer, con el objeto de aprehender las estrategias de la vida cotidiana de los entrevistados.

Las entrevistas han sido realizadas en una o varias sesiones, con el consentimiento de los informantes. Se recogieron las historias de vida siguiendo la estrategia de la "inducción analítica” hasta comprender el patrón de utilización de la seguridad social, políticas y programas sociales, tanto asistenciales como preventivos, por parte de las personas de mayor edad involucradas en la investigación.

Los temas fueron codificados y volcados en una matriz de datos obteniendo, de esta manera, redes de relaciones temáticas. El análisis de los datos se realizó a partir de las características ejemplificadoras (tipos) que surgieron de los relatos.

Trabajamos con una muestra intencional de varones y mujeres, de sectores sociales bajos, medios y altos, con el fin de obtener la diversidad de estrategias de supervivencia. Hemos realizado 33 entrevistas en profundidad, de las cuales 18 se efectuaron a mujeres y 15 a varones.

Esta investigación propuso un modelo en el cual las medidas cuantitativas fueron guiadas por hallazgos cualitativos y los hallazgos cualitativos fueron reexaminados con base en resultados cuantitativos.

Para la construcción de los datos cuantitativos, se operacionalizaron en las variables y sus dimensiones los conceptos codificados en la etapa cualitativa. Se construyó un cuestionario con preguntas cerradas y abiertas que se aplicó a una muestra representativa de la Ciudad de Buenos Aires. El cuestionario se conformó teniendo en cuenta variables sociodemográficas, económicas, educativas, la propiedad de la vivienda, la convivencia en el hogar, las fuentes de ingreso y la percepción de suficiencia de ingresos, así como la autopercepción de salud. También se indagó sobre las actividades de la vida cotidiana, las redes de apoyo, el sistema de seguridad social y los programas de prestaciones sociales, las 
actividades socio-recreativas que realizan y, por último, el conocimiento y opinión sobre las prestaciones sociales brindadas por el Estado y el uso de dichas prestaciones.

En la fase cuantitativa se realizó un muestreo probabilístico de la población mayor de la Ciudad de Buenos Aires. Se trabajó con un diseño multietápico: estratificado, conglomerado (puntos muestras), sistemático (vivienda) y azar simple (entrevistado). Se estratificó la Ciudad de Buenos Aires en comunas según niveles socioeconómicos. La muestra quedó conformada por 565 encuestados, 335 de los cuales son mujeres y 231 son hombres, teniendo en cuenta que el 22 \% (626.186 personas) de la población de la Ciudad de Buenos Aires son personas mayores de 60 años (INDEC, 2010).

Siguiendo el diseño de investigación propuesto, se preguntó en la encuesta sobre las representaciones de las prestaciones sociales a partir de la técnica de asociación de palabras.

La técnica se fundamenta en el reconocimiento de las funciones del lenguaje y su importancia en la construcción de la realidad social. A partir de lo que las personas dicen, se puede obtener un marco interpretativo de los diferentes discursos sobre los hombres y mujeres mayores de edad. Estos discursos señalan prejuicios y estereotipos que ponen de manifiesto las distintas prácticas que se derivan de ellos.

Según lo señalan algunos autores está fundamentada en la producción verbal y permite reducir la dificultad o los límites de la expresión discursiva. Consiste en pedir a la persona que produzca las palabras, expresiones o adjetivos que le vengan a la mente a partir de una palabra inductora. (Pinazo y Bueno, 2004: 25)

El carácter espontáneo y la dimensión proyectiva de esta producción, prosiguen los autores antedichos, permitirá acceder fácil y rápidamente a los elementos que constituyen el universo semántico del término o del objeto estudiado. Las asociaciones libres permiten acceder a los núcleos figurativos de la representación, están adaptadas para sondear los núcleos estructurales latentes de las Representaciones Sociales.

Para otros investigadores, (Perera Pérez, 2005: 14), las asociaciones de palabras favorecen la espontaneidad y naturalización de la situación de intercambio, al tiempo que permiten reducir en gran medida la apropiación por los sujetos de los contenidos representacionales de que es portador quien hace la entrevista. 
Para dar respuesta a los interrogantes planteados, a partir de la técnica de asociación de palabras analizamos las 1.251 respuestas brindadas por los entrevistados de ambos sexos y de sesenta y más años de edad, que habitan en la Ciudad Autónoma de Buenos Aires y a quiénes se les preguntó:

Para terminar le propongo un juego. Yo menciono una palabra y Ud. me dice las primeras tres ideas que le vienen a la cabeza.

39. Si yo digo: Prestaciones sociales, ¿qué cosa le viene a la cabeza?

\begin{tabular}{|l|l|}
\hline $\mathbf{1}$ & \\
\hline 2 & \\
\hline 3 & \\
\hline
\end{tabular}

Las preguntas abiertas sobre la representación de los programas sociales deja a los actores participantes en libertad para expresar sus motivaciones con sus propios matices, lo que permitió considerar las palabras y sus contextos. Los conceptos surgidos de las respuestas abiertas fueron codificados y clasificados a partir de los métodos de estadística textual. (Guerin-Pace, 1998: 80)

En una primera instancia, se confeccionó un listado de frecuencias con las formas léxicas repetidas contenidas en las respuestas de los encuestados y a continuación se construyó una lista depurada de dieciséis formas léxicas utilizadas por los encuestados. (Tabla 1)

También en la fase cuantitativa se llevó a cabo un segundo nivel de análisis sobre correspondencias múltiples a partir de los datos provenientes de las respuestas a las preguntas abiertas del cuestionario con el auxilio del software SPSS (Statistical Package for the Social Sciences).

El análisis de correspondencias proporciona una visión gráfica, simplificada, de la información que contienen los datos. Por su parte, estas representaciones visuales permiten situar a los individuos en un espacio determinado por las formas, posibilitando comparar los perfiles de sus respuestas, localizando aquellos más semejantes y las formas causantes de estas semejanzas. Del mismo modo, se detectan los sujetos que presentan más diferencias con respecto al resto y se explican las causas de estas divergencias. 
Al analizar la tabla de respuestas, se pueden estudiar las posiciones relativas de diferentes grupos de individuos en relación con el vocabulario empleado y caracterizarlos de acuerdo con las palabras utilizadas.

Además de mostrar una mera descripción de los motivos que esgrimen los adultos mayores para indicar el conocimiento y/o uso de los planes sociales, se pretendió caracterizar a los distintos grupos de individuos que utilizan formas similares o iguales en sus respuestas (cluster), a través de las categorías cualitativas. Esto se logra a partir de interpretar las formas generadas considerando las proximidades entre las categorías de las variables (edad, sexo, convivencia, nivel de educación, etcétera.) con respecto a las categorías conceptuales (visión positiva, mal funcionamiento, etcétera.) que son utilizadas simultáneamente por los encuestados.

\section{Caracterización de la población estudiada}

En cuanto al perfil demográfico de los encuestados, el 46\% era casado o unido con un predominio de varones (58\%). El 35\% de las mujeres eran viudas mientras que sólo el 17\% de los varones lo era. Más de la mitad de los entrevistados vivían solos o con su pareja (56\%). Pocos son los que convivían con cuidadores (1,2\%). En el grupo de los viejos-viejos las mujeres en general vivían solas. Con familia extensa cohabitaban el 36\% y con hermanos o amigos el 7\%. En relación al nivel educativo, alcanzaron estudios primarios un $33 \%$ de los casos, mientras que los estudios secundarios fueron completados por un $36 \%$ y un 31\% de las personas encuestadas cursaron estudios terciarios y universitarios.

Tal como se observa en la Figura 1, los planes de asistencia social más utilizados por las personas de mayor edad son: recepción de medicamentos (71\%), asistencia alimentaria a través de: bolsa de alimentos, asistencia a comedores, provisión de viandas y subsidio para alimentos (32,2\%); subsidios para servicios (24,6\%). 


\section{Figura}

1

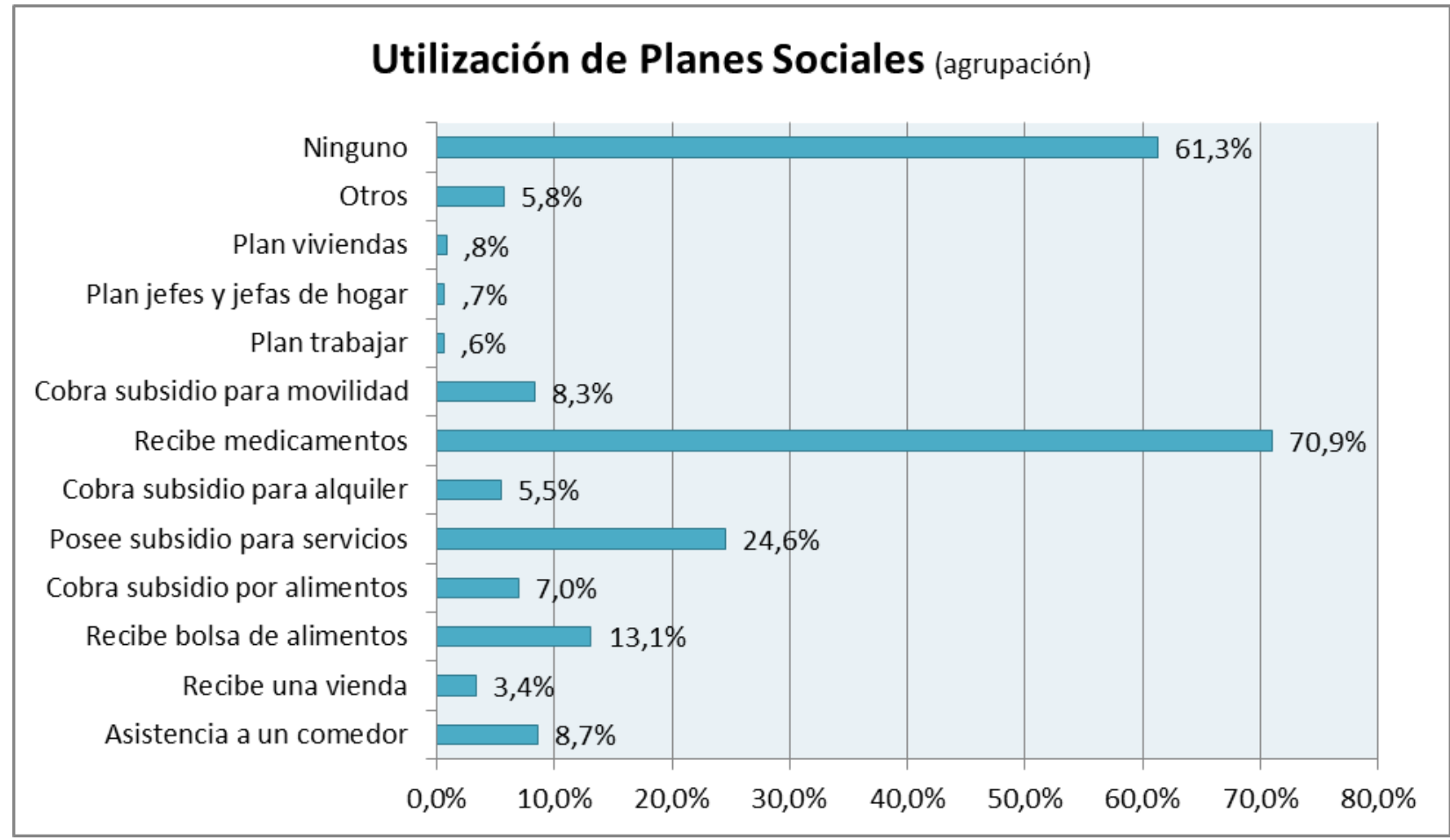

Elaboración propia. Datos encuesta UBACyT "Seguridad Social, Políticas Sociales y Redes de Apoyo en la Vejez. Un análisis integral entre programas Institucionales y actores"

Son las clases bajas quienes presentan un porcentaje mayor de utilización de asistencias relacionadas con la satisfacción de necesidades básicas como la alimentación (asisten a comedores, reciben viandas o bolsas de alimentos). En relación con la recepción de medicamentos la distribución entre las distintas clases socioeconómicas es muy similar (60,9\% la clase alta, 69,4\% la clase baja superior y 66,5\% la clase baja), solo presentando un porcentaje mayor la clase media con un $82 \%$. Con respecto a la edad, las personas mayores de 80 años son quienes más utilizan esta prestación. (82,9\%).

Más de la mitad de las personas de escasos recursos (aquellos que más los necesitan) no conocen ningún servicio o programa social, en tanto que el $2.9 \%$ de la clase baja indica que tiene un alto grado de conocimiento sobre los planes sociales. La mayor parte de la población estudiada no utiliza ningún plan social (61,3\%) y son los que poseen redes de apoyo familiares más fuertes los que no tienen conocimiento ni utilizan los programas asistenciales que proveen los apoyos formales o burocráticos. Se puede observar 
que aquellas personas mayores que no cuentan con apoyo emocional o afectivo por parte de su familia, asisten en mayor medida a comedores que quienes si lo tienen.

En la parte cualitativa de nuestro estudio, tres varones (Abraham ${ }^{6}, \operatorname{Marcos}^{7} \mathrm{y}$ Valentín $^{8}$ ) y cinco mujeres (Ana ${ }^{9}$, Estela ${ }^{10}$, Olga, Juana ${ }^{11}$ y Lola ${ }^{12}$ ) deben recurrir a programas de asistencia social para poder resolver las necesidades básicas de su existencia. El resto de los entrevistados, aún, siendo pobres, la resuelven desarrollando otras estrategias de supervivencia ligadas a sus grupos primarios. Los programas asistenciales utilizados son: comedores, viandas, bolsas de alimento, tarjetas para compra de supermercado, subsidios para compra de alimento, alquiler y/o transporte. Otras posibilidades con las que cuentan son las donaciones de dinero, acceso a medicación gratuita o subsidio para su compra. Las instituciones que brindan estos programas dependen de diversos organismos del Estado Nacional o Municipal, y/o de ONGs o mutuales. Resulta interesante observar que, los ancianos que acceden a las prestaciones a través de la mediación de ONGs o de la burocracia, logran una cobertura mayor y reciben un variopinto

\footnotetext{
${ }^{6}$ Abraham, tiene 81 años, nació en Varsovia es viudo y vive con un hijo adoptivo. Completó los estudios primarios y es beneficiario de una jubilación no contributiva. Recibe los siguientes planes: ayuda mensual para compra de alimentos; subsidio para alquiler y además participa de los talleres del comedor al que asiste. Cuenta con el servicio social de salud.

${ }^{7}$ Marcos tiene 91 años, nació en Polonia, es soltero y vive con un hermano adoptivo. Tiene estudios primarios completos. Recibe una jubilación contributiva y utiliza el servicio social de salud. Asiste a un comedor y recibe un subsidio para transporte y para alquiler. Participa en espectáculos y talleres de la asociación mutual a la que asiste.

${ }^{8}$ Valentín tiene 72 años, nació en el interior del país, es casado y vive con su esposa y dos nietos. Completó los estudios primarios. Trabaja voluntariamente en un centro de jubilados y realiza trabajos comunitarios en el barrio. Recibe una jubilación contributiva y recibe además una ayuda mensual para alimentación. Utiliza el servicio social de salud.

${ }^{9}$ Ana tiene 66 años, nació en la Ciudad de Buenos Aires, es soltera y comparte vivienda con otra mujer para disminuir los gastos. No completó los estudios secundarios. Percibe una pensión anticipada por razones de salud. Recibe un subsidio para pagar el alquiler. Asiste a un comedor gratuito y participa en los talleres de la asociación mutual a la que asiste. Atiende su salud a través del PROFE

${ }^{10}$ Estela tiene 64 años, nació en el conurbano de Buenos Aires, es viuda y vive con una tía. Tiene la secundaria incompleta y realizó estudios complementarios de cosmetología. Trabaja en su propio comercio y recibe una jubilación contributiva. Atiende su salud en el sistema privado.

${ }^{11}$ Juana tiene 78 años, nació en el interior del país es soltera y vive sola. Tiene estudios primarios incompletos y trabaja como costurera viviendo en el mismo taller donde trabaja. Percibe una pensión no contributiva y recibe tickets para comprar alimentos. Utiliza el servicio de salud PROFE.

${ }^{12}$ Lola tiene 73 años, nació en el interior del país es separada y vive sola. No posee escolaridad formal, aprendió a leer y escribir con una maestra particular, siendo adulta. Colabora voluntariamente en grupos de la tercera edad de un hospital público. Percibe una jubilación con moratoria. Asiste a un comedor y recibe un bolsón de alimentos además recibe dos subsidios para alimentos mensuales y una tarjeta para retirar mercadería de un supermercado. Utiliza el servicio social de salud.
} 
de programas en relación a aquellos que los tramitan por sí mismos. Al respecto, Lola nos cuenta:

"En este momento me parece que ya estoy necesitando que me ayuden.... (...) Nadie me cuida, estoy enferma con mi pierna, arrastrándome (...). Por eso quiero ver una asistente social..." (...) es una asistente social del Partido Justicialista. Ahí, yo fui una vez porque, antes que me había jubilado y había perdido mi documento. Entonces, de acá, de la unidad básica, me dio ¿cómo le puedo decir? Una recomendación para ir ahí y ahí hay una asistente social. (...) "Y usted, señora ¿por qué vino para que le hagamos el documento?" Y le digo "Porque mire, todavía no me sale la jubilación; es por eso que no tengo yo ahora, medios para sacarme el documento". Y cuando me vio que todavía yo andaba con una férula. Y ¿sabe qué hizo esta asistente social? Me hizo lo de la tarjeta para que me den la mercadería; entonces, yo, todavía no estaba jubilada; Entonces, me dijo "Yo le voy a dar una mano". Y cuando fui de vuelta, ella me dijo "Le voy a hacer dar la tarjeta para que le den los alimentos”.

También "yo voy al comedor de los jubilados. Voy todos los días, de lunes a viernes; está en el sótano. Pero yo no estoy conforme porque tengo que bajar la escalera y subir escaleras y a mí me cuesta muchísimo ahora. Y, todos los meses pero me dan el bolsón. Son más o menos 12 productos. Más o menos 12; no alcanzan a 15. El PAMI no crea que es muy bueno para la gente mayor ¿eh?..."

Asociado al tema de la salud los entrevistados de todos los sectores sociales utilizan programas preventivos (de integración social y socio participativos) que brindan las instituciones en las ellos participan.

En lo que se refiere a la salud física observamos que, en los centros de jubilados, los hospitales públicos o las mutuales, se organizan grupos para hacer caminatas o gimnasia adaptadas a las personas mayores. En la mayoría de los entrevistados se observa una preocupación por la actividad física que no sólo se desarrolla en esas instituciones sino que se practica, también, en forma individual. A través de los relatos, observamos que una buena parte de nuestros entrevistados recibe ayuda de tipo instrumental, material o de apoyo emocional por parte de ONGs, centros de Jubilados, hospitales públicos, iglesias, municipios u organizaciones de beneficencia. Al mismo tiempo, estas instituciones son mediadoras de las tareas voluntarias que los adultos mayores realizan en la comunidad.

\section{Sobre la representación de los planes sociales}


Como hemos expresado anteriormente, al analizar la tabla de respuestas, se pueden estudiar las posiciones relativas de diferentes grupos de individuos en relación con el vocabulario empleado y caracterizarlos de acuerdo con las palabras utilizadas. En este primer nivel de análisis se tuvieron en cuenta las frecuencias con que las palabras fueron dichas. Los temas predominantes son los que figuran en la siguiente Tabla:

Tabla $\mathrm{N}^{\circ} 1$

\begin{tabular}{|c|c|c|c|}
\hline Orden & Concepto & $\mathrm{N}^{\circ}$ & $\%$ \\
\hline 1 & $\begin{array}{l}\text { Valoración Negativa (a la deriva; ineficiencia; tarda; } \\
\text { trámites; arcaicas; no cumplen con su función de ayuda.) }\end{array}$ & 161 & 13,8 \\
\hline 2 & $\begin{array}{l}\text { Ayuda (dan ayuda; ayuda social; ayuda del gobierno; ayuda } \\
\text { necesaria; sirven; ayudan, beneficios sociales) }\end{array}$ & 138 & 11,8 \\
\hline 3 & $\begin{array}{l}\text { Exigencias (deben mejorar; estar mejor administrados; dar } \\
\text { más ayuda; más agilidad; deberían compenetrarse más, } \\
\text { deberían ser más objetivas) }\end{array}$ & 127 & 10,8 \\
\hline 4 & $\begin{array}{l}\text { Instituciones (PAMI, Obra Social; } \\
\text { Comunitario, Visitadora Social) }\end{array}$ & 97 & 8,3 \\
\hline 5 & No conoce, No usa, Nada & 96 & 8,2 \\
\hline 6 & $\begin{array}{l}\text { Servicios (viajes; subsidios; vivienda; alimentos; comedor; } \\
\text { salud; remedios) }\end{array}$ & 70 & 6,0 \\
\hline 7 & $\begin{array}{l}\text { Valoración relativa: (tienen su pros y sus contras; regular; } \\
\text { algunas buenas otras no; algunos se quejan; algunas son } \\
\text { negativas; incompletas, insuficientes.) }\end{array}$ & 65 & 5,5 \\
\hline 8 & $\begin{array}{l}\text { Corrupción (burocracia; corrupción; desastre; horror; } \\
\text { horrible; estafa; mal desempeño de los funcionarios) }\end{array}$ & 64 & 5,4 \\
\hline 9 & $\begin{array}{l}\text { Valoración Positiva: (bien; muy bien; buena calidad; está } \\
\text { bien; positivo; solidaridad; gratuitas) }\end{array}$ & 59 & 5,1 \\
\hline 10 & $\begin{array}{l}\text { Necesidad (son necesarias; precisamos; tiene que haber, } \\
\text { hacen falta) }\end{array}$ & 56 & 4,8 \\
\hline 11 & $\begin{array}{l}\text { Política (cumplen funciones políticas; propaganda; Estado; } \\
\text { gobierno; gobierno de la ciudad; plata estatal) }\end{array}$ & 51 & 4,3 \\
\hline 12 & Prestaciones de salud (salud, remedios, medicamentos) & 49 & 4,2 \\
\hline 13 & Pobreza (para los necesitados, para los pobres) & 36 & 3,1 \\
\hline 14 & $\begin{array}{lll}\begin{array}{l}\text { Prestaciones sociales } \\
\text { computadoras, viajes) }\end{array} & \text { (sociorecreativas; educativas, } \\
\end{array}$ & 21 & 1,8 \\
\hline 15 & $\begin{array}{l}\text { Para los viejos (para los mayores; para los viejos, cuidados } \\
\text { para los mayores) }\end{array}$ & 21 & 1,8 \\
\hline 16 & $\begin{array}{l}\text { Innecesarias (no hay necesidad; beneficiencia; me preocupa; } \\
\text { tienen que desaparecer; se necesitan más fuentes de trabajo.) }\end{array}$ & 17 & 1,5 \\
\hline 17 & Otros & 44 & 3,7 \\
\hline
\end{tabular}


Al focalizar sobre las palabras emitidas por las personas mayores en relación a los programas sociales vemos que, en primer lugar se nuclean aquellas asociadas a una valoración negativa de los programas sociales para las personas mayores; en segundo término, se indica que los programas representan una “ayuda necesaria” y que “deberían mejorar” se coloca en tercer lugar de la lista.

Con respecto al sexo de los encuestados, en los varones prevalece una visión negativa y las intenciones de “deberían mejorar” se nuclean en segundo término. Las mujeres, en tanto, piensan que son una ayuda aunque coinciden con los varones en una valoración negativa y que por lo tanto, tendrían que mejorar.

Al posicionarnos sobre la visión que las personas mayores tienen sobre los programas sociales según su nivel de educación, se observa que, quiénes accedieron a los niveles primarios educativos opinan según el siguiente orden: 1) son una ayuda; 2) visión negativa; 3) no conoce y 4) visión positiva. En las personas que completaron sus estudios secundarios, las palabras se nuclean en torno a que son una ayuda en primer lugar y una visión negativa en segundo término. Por último, aquellos que accedieron a una educación superior muestran una visión negativa en primer lugar y en segundo lugar opinan que son una ayuda necesaria y asocian estos programas a las instituciones cuyo objetivo es para la vejez.

Centrados en el análisis sobre la valoración positiva de los planes sociales vemos que la expresan el 45,8\% de los que cursaron los estudios primarios; el 37,1\% de los que tienen niveles educativos secundarios y el 17,1\% de los que alcanzaron niveles superiores de educación. En síntesis, podemos decir que las personas mayores que tienen menor escolaridad (suelen ser quienes más necesitan o pueden necesitar de recurrir a ellos) tienen una opinión más favorable en relación a los programas sociales que las personas mayores con más altos niveles educativos (que suelen pensar que los programas sociales representan un gasto con uso político de los mismos).

El análisis de correspondencias múltiples nos permitió generar el siguiente diagrama, del cual extraer una tipología de la visión de los adultos mayores en relación con 
los programas sociales. En particular, mostramos la visión con respecto a las políticas sociales para las personas mayores.

Figura 2: Diagrama conjunto de puntos de categorías

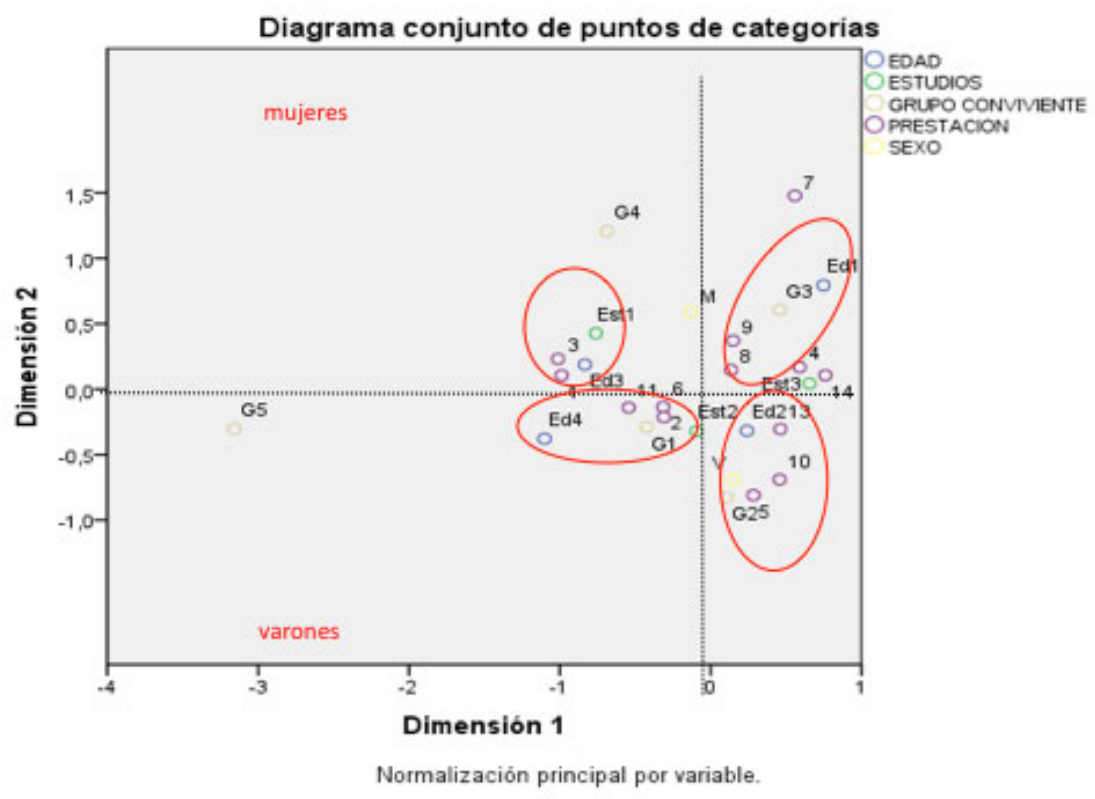

Surge claramente de la Figura 2 que las representaciones y opiniones con respecto a las políticas sociales se polarizan en función del nivel de educación obtenido y del grupo de edad. Se destaca que las personas a cargo de cuidadores - G5 - aparecen alejados en el diagrama, sin poder incluirlos en un grupo específico, lo que nos permite inferir que no están en condiciones de emitir sus opiniones.

- Grupo 1: Compuesto mayoritariamente por mujeres y del grupo de personas de 60 a 64 años con un nivel de educación superior que viven con familia extensa destacan una valoración negativa o regular sobre los planes sociales específicos. Entienden, que las prestaciones deberían mejorar.

- Grupo 2: Compuesto mayoritariamente por mujeres y personas de 75 a 79 años con estudios primarios que viven en hogares extendidos dicen tener una visión positiva de los programas sociales y consideran que los mismos son una gran ayuda para las personas de mayor edad. 
- Grupo 3: Los varones y personas entre 65 y 74 años de edad con un nivel de educación media y que viven con pareja asocian los planes sociales con la obra social de los jubilados, con los servicios y prestaciones viajes, los paseos y también, con una fuerte visión crítica en relación con situaciones de corrupción.

- Grupo 4: Los varones y las personas de 80 años y más con un nivel de educación media que viven solos reflejan una visión negativa asociando los planes sociales a políticas de propaganda de los gobiernos de la ciudad y nacional, aunque, al mismo tiempo que indican que son una necesidad para los pobres.

\section{Conclusión}

En el análisis de las palabras asociadas hemos visto que la representación social sobre los programas sociales presenta imágenes y opiniones tanto positivas como negativas, fuertemente relacionadas con el nivel educativo de las personas mayores, variable que tiene un peso ineludible en la definición de la posición social al que pertenecen las personas encuestadas.

Como fuera señalado, al haber aplicado una doble perspectiva, nos ha sido posible destacar la variedad de los elementos comunes dentro del campo representacional construido por el grupo al que pertenecen los integrantes de la muestra $y$, las diferencias producidas en el entrecruzamiento de las representaciones sobre los programas sociales estatales y las particulares creencias y significaciones referidas a los mismos, conformadas por el contexto social y político.

Nuestros hallazgos indican que la visibilidad de los planes sociales y su mirada positiva o negativa se asocian y dependen de su conocimiento, su uso y el grado de satisfacción de necesidades que proveen a las personas mayores. En este sentido, la población que tiene necesidades de ayuda social, acrecienta su mirada positiva de los planes. En oposición, las personas que no necesitan este tipo de ayuda, tienden a acrecentar su mirada negativa y suelen identificar a los planes sociales como un gasto orientado a la utilización como herramienta de la propaganda política.

Por último, hemos observado que aquellas personas mayores que pueden contar con la orientación de un trabajador social; de una Ong; una iglesia, un partido político, entre otras posibilidades, logrará obtener mayores beneficios sociales que aquellos que se 
encuentran solos frente a la gestión institucional, condicionando la visibilidad y conocimiento de los programas sociales para ellos destinados.

\section{Referencias bibliográficas}

ABRIC, Jean-Claude. (2001), Pratiques sociales et représentations, Paris: Presses Universitaires de France.

ADELANTADO, José (2008) Por una gestión inclusiva de la política social. En Magdalena CHIARA y Mercedes DI VIRGILIO. (Orgs) Gestión de la Política Social. Conceptos y Herramientas. Buenos Aires. Prometeo.

BLAISON, Christophe, CHASSARD, Delfine, KOP, Jean-Luc, \& GANA, Kamel. (2006). L'IAT (Implicit Association Test) ou la mesure des cognitions sociales implicites: Revue critique de la validité et des fondements théoriques des scores qu'il produit / Implicit Association Test or the measure of implicit social cognition: A critical review of the validity and the theoretical basement of its scores, L'Année Psychologie, 106(2), (305336).

CHERNOBILSKY, Lilia., (2019) Estrategia informática para la combinación de datos cualitativos y cuantitativos: ¿Software mixto o combinación desoftware? en I. Vasilachis de Gialdino (Coord.), Estrategias de investigación cualitativa 2, Barcelona, Gedisa. Pp 327371.

DANANI, Claudia, y GRASSI, Estela, (2018) "Protección social institucionalizada". Capítulo en el libro. La Argentina en el Siglo XXI. Como somos, vivimos y convivimos en una sociedad desigual. (Coord. Juan Ignacio PIOVANI y Agustin SALVIA) Siglo XXI Editores. Ciudad de Buenos Aires. Pp. 593-623.

DANANI, Claudia, (2008) La gestión de la política social: un intento de aportar a su problematización. En Magdalena CHIARA y Mercedes DI VIRGILIO. (Orgs) Gestión de la Política Social. Conceptos y Heramientas (pp 25-51). Buenos Aires. Prometeo.

DUVEEN, Gerard \& LLOYD, Barbara. (1990). Social Representations and the Development of Knowledge, Cambridge: Cambridge University Press.

FLAMENT, Claude, (1994) Représentation sociale, consensus et corrélation. Remarques à partir des remarques en E. H. Witte. Papers on Social Representations, 3, (184-193). Disponible en http://www.psr.jku.at/

GASTRON, Liliana, MONCHIETTI, Alicia, y ODDONE, María Julieta, (2012) "Representaçòes sociais sobre homens e mulheres na velice” Capítulo en libro Luiz Fernando RANGEL TURA y Antonia OLIVEIRA SILVA “Envelhecimento e Representaçòes sociais. Universidad de Río de Janeiro.Río de Janeiro. Editorial Quartet. (pp.:117-139) 
JODELET, Denisse. (ed.) (1989) Les représentations sociales, Paris: Presses Universitaires de France.

LEHR, Ursula. (1999). Les implicationspolitiques de la longévité. En: C. Jasmin et R. Butler, (Eds.) Longévité et qualité de vie, Défis et enjeux (pp. 341-357). Paris: Institut Synthélabo.

LEHR, Ursula. (2015). Conferencia Magistral. Congreso Internacional Sobre Vejez y Envejecimiento. Junio de 2015. México: Universidad Nacional Autónoma de México. [consultado el 03 Septiembre 2015] disponible en: http:// seminarioenvejecimiento.unam.mx/Congreso/ Morales, J. F. \& Moya, M. C. (2007). Definición de Psicología social.

LOMBARDO, Enrique, MONCHIETTI, Alicia. (2015) Niveles de reconocimiento que integran las representaciones sociales. Un estudio sobre la polifasia cognitiva. En Revista Perspectiva en Psicología. Vol. 12 N². Noviembre 2015 pp.50-56.

MIGUEL, Isabel; VALENTIN, Joaquín Pires \& CARUGATI, Felice. (2010) Intelligence and its development: Social representations and social identities. Papers on Social Representations, 19, (20.1-20.33).

MONCHIETTI, Alicia., SANCHEZ, Mirtha, LOMBARDO, Enrique. KRZEMIEN Deisy. (2009). Funcionamiento cognitivo en la vejez. Su campo representacional. Límite: Revista de Filosofía y Psicología, Universidad de Tarapacá.

MOSCOVICI, Serge. (1986) Psicología Social. Tomos I y II, Barcelona: Paidos.

ODDONE, María Julieta, (2014) Ancianas cuidadoras, redes y estrategias en el uso de programas sociales. En revista Cadernos de pesquisa. Vol. 44 - $\mathrm{N}^{\circ}$ 152- junio 2014, pp.354-377.

ODDONE, M.J. \& CHERNOBILSKY, L. (2015). Estrategia informática para la combinación de datos cualitativos y cuantitativos. Una visión de los adultos mayores sobre Políticas Sociales. Revista Ciencia y Técnica, Universidad Siglo 21, Córdoba, Argentina 7(2) disponible en: http://www.21.edu.ar/revista-ciencia-tecnica-numeros.html

ODDONE, María Julieta, POCHINTESTA, Paula, (2017) Actitudes de los Adultos Mayores de la Ciudad de Buenos Aires ante las políticas y los programas para la vejez. En revista Perspectivas en Psicología. Vol. 14 - N 1- junio 2017, pp105-114.UNMP.Mar del Plata.

ODDONE, María Julieta, (2018) Condiciones de vida de las personas mayores. Capítulo en el libro. La Argentina en el Siglo XXI. Como somos, vivimos y convivimos en una sociedad desigual. (Coord. Juan Ignacio PIOVANI y Agustin SALVIA) Siglo XXI Editores. Ciudad de Buenos Aires. Pp. 593-623. 
PERERA PEREZ, Maricela, A propósito de las representaciones sociales. Apuntes teóricos, trayectoria y actualidad. Disponible en :

http://bibliotecavirtual.Clacso.org.ar/ar/libros/cuba/cips/cuadales05/Caudales/ARTICULO/ ArticulosPDF/02PO75.pdf.

PINAZO, Sacramento y BUENO, José, (2004), Reflexiones acerca del final de la vida, Revista Multidisciplinaria de Gerontología, 14 (1), (22-26).

RENEDO, Alicia, (2010) Polyphony and Polyphasia in Self and Knowledge Papers on Social Representations. 19 (12) $(1-21)$.

ROSE, Diana, EFRAIN, Danielle, GERVAIS, Marie-Claude, JOFFE, Helene, JOVCHELOVITCH, Sandra \& MORANT, Nicola. (1995), Questioning consensus in social representation theory. Papers on Social Representation, 4, (150-156).

Recebido 23/04/2019

Aprovado 28/05/2019 